\title{
MASALAH EIGEN DAN EIGENMODE MATRIKS ATAS ALJABAR MIN-PLUS
}

\section{Eigen Problem and Eigenmode Matrix over Min-Plus Algebra}

\author{
Eka Widia Rahayu ${ }^{1 *}$, Siswanto ${ }^{2}$, Santoso Budi Wiyono ${ }^{3}$ \\ 1,2,3 Program Studi Matematika, Fakultas Matematika dan Ilmu Pengetahuan Alam, Universitas Sebelas Maret \\ Jln. Ir. Sutami No 36A Kentingan, Surakarta, 57126, Indonesia
}

Corresponding author e-mail: 1*ekawidia@student.uns.ac.id

\begin{abstract}
Abstrak
Masalah eigen dan eigenmode adalah komponen penting yang berhubungan dengan matriks persegi. Pada aljabar maks-plus suatu matriks persegi dapat direpresentasikan dalam bentuk graf yang dinamakan graf komunikasi. Graf komunikasi dapat berupa graf strongly connected dan graf tidak strongly connected. Matriks representasi dari graf strongly connected disebut matriks tak tereduksi sedangkan matriks representasi dari graf tidak strongly connected disebut matriks tereduksi. Tujuan dari penelitian ini adalah menyusun langkah-langkah untuk menentukan nilai eigen dan vektor eigen matriks tak tereduksi atas aljabar min-plus serta eigenmode matriks tereduksi reguler atas aljabar min-plus. Aljabar min-plus memiliki struktur yang isomorpik dengan aljabar maks-plus. Oleh karena itu, masalah eigen dan eigenmode matriks atas aljabar min-plus dapat ditentukan berdasarkan teori nilai eigen, vektor eigen dan eigenmode matriks atas aljabar maks-plus. Hasil dari penelitian ini diperoleh langkah-langkah untuk menentukan nilai eigen dan vektor eigen matriks tak tereduksi atas aljabar min-plus serta algoritme eigenmode matriks tereduksi reguler atas aljabar min-plus.
\end{abstract}

Kata Kunci : aljabar min-plus, masalah eigen, eigenmode

\begin{abstract}
Eigen problems and eigenmode are important components related to square matrices. In max-plus algebra, a square matrix can be represented in the form of a graph called a communication graph. The communication graph can be strongly connected graph and a not strongly connected graph. The representation matrix of a strongly connected graph is called an irreducible matrix, while the representation matrix of a graph that is not strongly connected is called a reduced matrix. The purpose of this research is set the steps to determine the eigenvalues and eigenvectors of the irreducible matrix over min-plus algebra and also eigenmode of the regular reduced matrix over min-plus algebra. Min-plus algebra has an ispmorphic structure with max-plus algebra. Therefore, eigen problems and eigenmode matrices over min-plus algebra can be determined based on the theory of eigenvalues, eigenvectors and eigenmode matrices over max-plus algebra. The results of this research obtained steps to determine the eigenvalues and eigenvectors of the irreducible matrix over min-plus algebra and eigenmode algorithm of the regular reduced matrix over min-plus algebra.
\end{abstract}

Keywords: min-plus algebra, eigen problem, eigenmode 


\section{PENDAHULUAN}

Aljabar maks-plus adalah himpunan $\mathbb{R} \cup \varepsilon$ dengan $\mathbb{R}$ merupakan himpunan semua bilangan real dan $\varepsilon=-\infty$ yang dilengkapi dengan operasi maksimum $(\oplus)$ dan plus $(\otimes)$. Aljabar maks-plus dinotasikan dengan $\mathbb{R}_{\text {maks }}=\left(\mathbb{R}_{\varepsilon}, \oplus, \otimes\right)$ merupakan semifield idempoten [1]. Operasi-operasi yang terdapat pada aljabar maks-plus dapat diperluas ke dalam himpunan matriks. Himpunan matriks berukuran $m \times n$ yang komponen-komponennya merupakan elemen $\mathbb{R}_{\varepsilon}$ disebut himpunan matriks atas aljabar maks-plus yang dinotasikan dengan $\mathbb{R}_{\text {maks }}^{m \times n}$.

Masalah nilai eigen, vektor eigen dan eigenmode adalah komponen penting yang berhubungan dengan matriks persegi. Matriks persegi adalah matriks yang mempunyai jumlah kolom dan baris sama. Pada aljabar maks-plus suatu matriks persegi dapat direpresentasikan dalam bentuk graf yang dinamakan graf komunikasi. Graf komunikasi dapat berupa graf strongly connected dan graf tidak strongly connected. Graf strongly connected merupakan graf yang setiap node-nya dapat dicapai dari setiap node yang lain. Matriks representasi dari graf strongly connected disebut matriks tak tereduksi sedangkan matriks representasi dari graf tidak strongly connected disebut matriks tereduksi.

Penentuan nilai eigen matriks tak tereduksi dengan matriks tereduksi memiliki perbedaan. Nilai eigen dari matriks tak tereduksi merupakan bobot rata-rata maksimum dari semua sirkuit pada graf komunikasi. Namun, tidak semua matriks tereduksi memiliki nilai eigen yang merupakan bobot rata-rata maksimum dari sirkuit yang ada. Eigenmode tergeneralisasi merupakan pasangan vektor hasil perumuman dari nilai eigen dan vektor eigen matriks tak tereduksi [2]. Oleh karena itu, permasalahan nilai eigen matriks tereduksi dapat diselesaikan dengan menentukan eigenmode tergeneralisasi.

Masalah nilai eigen, vektor eigen dan eigenmode matriks atas aljabar maks-plus dapat diaplikasikan pada kehidupan sehari-hari seperti untuk menyelesaikan masalah penjadwalan [3] dan pengaturan sistem antrian [4]. Masalah nilai eigen dan vektor eigen matriks atas aljabar maks-plus sudah banyak dibahas pada penelitian sebelumnya di antaranya pada penelitian [5], [6], [7], [8], dan [9]. Sementara itu, eigenmode matriks atas aljabar maks-plus dibahas pada penelitian [2], [10] dan [11]. Aljabar min-plus memiliki struktur yang isomorpik dengan aljabar maks-plus. Oleh karena itu, nilai eigen, vektor eigen dan eigenmode matriks atas aljabar min-plus dapat ditentukan berdasarkan teori nilai eigen, vektor eigen dan eigenmode matriks atas aljabar maks-plus. Aljabar min-plus telah dibahas pada penelitian [12] dan [13]. Nascihuddin [14] pada tahun 2017 membahas mengenai algoritme pangkat untuk menentukan masalah eigen matriks atas aljabar min-plus.

Tujuan penelitian ini adalah menyusun langkah-langkah untuk menentukan nilai eigen dan vektor eigen matriks tak tereduksi atas aljabar min-plus serta menentukan eigenmode matriks tereduksi reguler atas aljabar min-plus. Manfaat dari penelitian ini yaitu untuk menambah pengetahuan mengenai aljabar min-plus khususnya masalah nilai eigen, vektor eigen dan eigenmode.

\section{METODE PENELITIAN}

Metode penelitian yang digunakan yaitu studi literatur dengan menggunakan referensi berupa jurnal, artikel, dan buku. Langkah-langkah yang dilakukan dalam penelitian ini adalah mempelajari materi yang menjadi dasar dalam penelitian ini yang meliputi teori graf, masalah eigen dan eigenmode, algoritme eigenmode matriks atas aljabar maks-plus, aljabar min-plus dan matriks atas aljabar min-plus, menyusun langkah-langkah untuk menentukan nilai eigen dan vektor eigen matriks tak tereduksi atas aljabar min-plus. Setelah itu, memformulasikan persamaan rekurensi nonhomogen dalam aljabar min-plus berdasarkan persamaan rekurensi nonhomogen dalam aljabar maks-plus. Kemudian menentukan algoritme eigenmode matriks tereduksi reguler atas aljabar min-plus.

\section{HASIL DAN PEMBAHASAN}

\subsection{Nilai Eigen dan Vektor Eigen Matriks Tak Tereduksi atas Aljabar Min-Plus}

Diberikan definisi nilai eigen dan vektor eigen yang diambil dari [12].

Definisi 1. Diberikan $A \in \mathbb{R}_{\min }^{n \times n}$. Jika $\lambda \in \mathbb{R}_{\min }$ dan $\boldsymbol{v} \in \mathbb{R}_{\min }$ sedemikian sehingga $\boldsymbol{v}$ mempunyai sedikitnya satu entri berhingga dan 


$$
A \otimes v=\lambda \otimes v
$$

maka $\lambda$ merupakan nilai eigen dari A dan $\boldsymbol{v}$ merupakan vektor eigen yang bersesuaian .

Definisi 2. Diberikan $C(A)$ yang menyatakan himpunan dari semua sirkuit dari graf $G(A)$.

$$
\lambda=\min _{p \in C(A)} \frac{\|p\|_{w}}{\|p\|_{l}}
$$

Definisi 3. Diberikan $A \in \mathbb{R}_{\min }^{n \times n}$ dan $\lambda$ didefinisikan seperti pada Definisi 1, maka didefinisikan matriks $A_{\lambda}$ sebagai berikut

$$
A_{\lambda}=a_{i j}-\lambda
$$

matriks $A_{\lambda}^{+}$didefinisikan sebagai

$A_{\lambda}^{*}$ didefinisikan sebagai

$$
A_{\lambda}^{+}=A_{\lambda} \oplus^{\prime} A_{\lambda}^{\otimes 2} \oplus^{\prime} \ldots \oplus^{\prime} A_{\lambda}^{\otimes n}
$$

$$
A_{\lambda}^{*}=E \oplus^{\prime} A_{\lambda}^{+}
$$

Berdasarkan teori nilai eigen dan vektor eigen matriks atas aljabar maks-plus, nilai eigen $\lambda$ dari matriks tak tereduksi $A \in \mathbb{R}_{\min }^{n \times n}$ dan vektor eigen yang bersesuaian ditentukan melalui langkah-langkah sebagai berikut.

1. Menentukan graf komunikasi dari matriks $A \in \mathbb{R}_{\text {min }}^{n \times n}$,

2. menentukan nilai eigen, dalam menentukan nilai eigen $\lambda$ dapat dilakukan berdasarkan Definisi 2,

3. memperhatikan sirkuit (c,c) untuk suatu $1 \leq c \leq n$ yang merupakan sirkuit kritis dari $G(A)$,

4. menentukan $A_{\lambda}$ dan matriks $A_{\lambda}^{*}$,

5. vektor eigen dari $A$ adalah kolom c dari matriks $A_{\lambda}^{*}$.

\subsection{Eigenmode}

Matriks yang dibahas adalah matriks reguler yaitu matriks yang disetiap baris setidaknya memuat satu entri tidak sama dengan $\varepsilon$. Berikut diberikan definisi mengenai eigenmode matriks tereduksi reguler yang diambil dari [15].

Definisi 4. Suatu pasangan vektor $(\boldsymbol{\eta}, \boldsymbol{v}) \in \mathbb{R}^{n} \times \mathbb{R}^{n}$ disebut eigenmode tergeneralisasi dari matriks reguler A jika untuk setiap $k \geq 0$ memenuhi

$$
A \otimes(k \times \boldsymbol{\eta}+\boldsymbol{v})=(k+1) \times \boldsymbol{\eta}+\boldsymbol{v}
$$

Eigenmode tergeneralisasi disebut juga dengan eigenmode merupakan perluasan dari nilai eigen dan vektor eigen matriks tak tereduksi.

\subsection{Persamaan Rekurensi Nonhomogen}

Untuk mengetahui nilai eigen dari matriks tereduksi atas aljabar min-plus, terlebih dahulu dipelajari perluasan dari relasi rekurensi $x(k+1)=A \otimes x(k)$ dengan $A$ adalah matriks tak tereduksi. Oleh karena itu berdasarkan teori relasi rekurensi nonhomogen matriks atas aljabar maks-plus, diperoleh teorema berikut.

Teorema 1. Diperhatikan relasi rekurensi nonhomogen sebagai berikut

$$
\boldsymbol{x}(k+1)=A \otimes \boldsymbol{x}(k) \bigoplus^{\prime} \bigoplus_{j=1}^{\prime m} B_{j} \otimes \boldsymbol{u}_{j}(k),
$$

dengan $A \in \mathbb{R}_{\text {min }}^{n \times n}$ merupakan matriks tak tereduksi yang mempunyai nilai eigen $\lambda$ atau $A \in \mathbb{R}_{\text {min }}$ dimana $A=\varepsilon$ dengan $\lambda=\varepsilon, B_{j} \in \mathbb{R}_{\text {min }}^{n \times m_{j}}$ dimana $j \in m$ dengan $m_{j} \geq 1$ memenuhi $B_{j} \neq \varepsilon$, sedangkan $\boldsymbol{u}_{j}(k) \in$ $\mathbb{R}_{\text {min }}^{m_{j}}$ memenuhi $\boldsymbol{u}_{j}(k)=\tau_{j}^{k} \otimes \boldsymbol{w}_{j}(k), k \geq 0$ dengan $\boldsymbol{w}_{j} \in \mathbb{R}_{\text {min }}^{m_{j}} \quad$ skalar $\tau_{j} \in \mathbb{R}, \quad$ ditunjukkan $\tau=$ $\bigoplus_{j \in \underline{m}}^{\prime} \tau_{j}$ maka terdapat bilangan bulat $K \geq 0$ dan vektor $\boldsymbol{v} \in \mathbb{R}^{n}$ sedemikian sehingga barisan $\boldsymbol{x}(k)=$ $\mu^{\otimes k} \otimes v$, dengan $\mu=\lambda \oplus^{\prime} \tau$ memenuhi persamaan rekurensi (1) untuk setiap $k \geq K$. 
Bukti. Untuk membuktikan hal tersebut, ditentukan untuk dua kasus berbeda, yaitu $\lambda>\tau$ dan $\lambda \leq \tau$.

Kasus $\lambda>\tau$. Ambil $v$ sebagai vektor eigen dari matriks $A$ yang bersesuaian dengan nilai eigen $\lambda$. Pengambilan $\boldsymbol{v}$ memenuhi $\boldsymbol{v} \otimes \lambda<\bigoplus_{j=1}^{m \prime} B_{j} \otimes \boldsymbol{w}_{j}$. Selanjutnya, ambil $\mu=\lambda>\tau_{j}$ untuk semua $j \in \underline{m}$, sedemikian sehingga untuk semua $k \geq 0$ memenuhi

$$
\mu \otimes \boldsymbol{v} \otimes \mu^{\otimes k}=A \otimes \boldsymbol{v} \otimes \mu^{\otimes k}<\oplus_{j=1}^{\prime m} B_{j} \otimes \boldsymbol{w}_{j} \otimes \mu^{\otimes k} \leq \oplus_{j=1}^{\prime m} B_{j} \otimes \boldsymbol{w}_{j} \otimes \tau_{j}^{\otimes k} .
$$

dengan kata lain,

$$
\boldsymbol{v} \otimes \mu^{\otimes(k+1)}=A \otimes \boldsymbol{v} \otimes \mu^{\otimes k}<\oplus_{j=1}^{\prime m} B_{j} \otimes \boldsymbol{w}_{j} \otimes \tau_{j}^{\otimes k}
$$

Oleh karena itu, relasi rekurensi (1) terpenuhi untuk semua $k \geq 0$ dengan $x(k)=\boldsymbol{v} \otimes \mu^{\otimes k}$ dan $\boldsymbol{u}_{\boldsymbol{j}}(k)=$ $\boldsymbol{w}_{j} \otimes \tau_{j}^{\otimes k}$ untuk $j \in \underline{m}$.

Kasus $\lambda \leq \tau$. Misalkan $\tau=\bigoplus_{j \in \underline{m}}^{\prime} \tau_{j}$ dan nilai minimum diperoleh untuk $\tau$ ke- $r$ pertama, yang akan terpenuhi dengan penomoran ulang dari barisan $\boldsymbol{u}_{j}(k), j \in \underline{m}$. Kemudian ambil vektor $\boldsymbol{v}$ yang memenuhi

$$
\boldsymbol{v}=A_{\tau} \otimes \boldsymbol{v} \oplus^{\prime} \oplus_{j=1}^{\prime r}\left(B_{j}\right)_{\tau} \otimes \boldsymbol{w}_{j}
$$

dimana $A_{\tau}$ dan $\left(B_{j}\right)_{\tau}, j \in \underline{m}$ didapatkan dari matriks $A$ dan $\left(B_{j}\right)$ dengan mengurangi $\tau$ terhadap semua elemen terbatasnya. Karena $\lambda \leq \tau$, maka graf komunikasi dari $A_{\tau}$ hanya memuat sirkuit dengan bobot nonpositif. Oleh karena itu, solusi dari $\boldsymbol{v}$ ada, kemudian karena $\left(A_{\tau}\right)^{*}$ adalah terbatas $\left(A_{\tau}\right.$ adalah tak tereduksi) dan $\bigoplus_{j=1}^{\prime r}\left(B_{j}\right)_{\tau} \otimes \boldsymbol{w}_{j}$ memuat setidaknya satu elemen terbatas, maka $\boldsymbol{v}$ terbatas. Namun hal ini berakibat

$$
\boldsymbol{v} \otimes \tau=A \otimes \boldsymbol{v} \oplus^{\prime} \oplus^{\prime r=1} B_{j} \otimes \boldsymbol{w}_{j}
$$

Kemudian, dengan mengambil $\mu=\tau=\tau_{j}, j=1,2, \ldots, r$, untuk semua $k \geq 0$ yang memenuhi

$$
\boldsymbol{v} \otimes \mu^{\otimes(k+1)}=A \otimes \boldsymbol{v} \otimes \mu^{\otimes k} \oplus^{\prime} \oplus_{j=1}^{\prime r} B_{j} \otimes \boldsymbol{w}_{j} \otimes \tau_{j}^{k}
$$

akan memenuhi pertidaksamaan

$$
\boldsymbol{v} \otimes \mu^{\otimes(k+1)} \geq A \otimes \boldsymbol{v} \otimes \mu^{\otimes k} \oplus^{\prime} \oplus_{j=1}^{\prime m} B_{j} \otimes \boldsymbol{w}_{j} \otimes \tau_{j}^{k},
$$

Namun, karena $\mu>\tau_{j}$ untuk $j=r+1, r+2, \ldots, m$ terdapat bilangan bulat $K \geq 0$ sedemikian sehingga untuk semua $k \geq K$ memenuhi

$$
\boldsymbol{v} \otimes \mu^{\otimes(k+1)} \leq \oplus_{j=r+1}^{\prime m} B_{j} \otimes \boldsymbol{w}_{j} \otimes \tau_{j}^{k}
$$

sehingga untuk semua $k \geq K$ pertidaksamaan (3) adalah persamaaan. Oleh karena itu, persamaan relasi rekurensi (1) terpenuhi untuk semua $k \geq K$.

Matriks tereduksi $A$ dapat disajikan ke dalam matriks bentuk normal. Selanjutnya, diambil vektor $\boldsymbol{x}(k)$ yang bersesuaian dengan matriks bentuk normal, yaitu

$$
\boldsymbol{x}(k)=\left(\begin{array}{c}
x_{1}(k) \\
x_{2}(k) \\
\vdots \\
x_{q}(k)
\end{array}\right) .
$$

Matriks bentuk normal dari matriks tereduksi $A$ dapat ditunjukkan dalam relasi rekurensi nonhomogen sebagai berikut

$$
\boldsymbol{x}_{\boldsymbol{i}}(k+1)=A_{i i} \otimes \boldsymbol{x}_{i}(k) \oplus^{\prime} \bigoplus_{j=i+1}^{\prime q} A_{i j} \otimes x_{j}(k) ; i \in q, k \geq 0 .
$$


Selanjutnya nilai eigen dan vektor eigen dari $A$ memenuhi Teorema 2.

Teorema 2. Jika pada relasi rekurensi (4) matriks $A_{q q}$ merupakan matriks tak tereduksi dan untuk $i \in \underline{q-1}$ matriks $A_{i i}$ adalah tak tereduksi atau samadengan matriks $\mathcal{E}^{\prime}$ maka terdapat skalar $\xi_{1}, \xi_{2}, \cdots, \xi_{q}$ dan vektor $v_{1} . v_{2}, \ldots, v_{q}$ sedemikian sehingga

$$
\boldsymbol{x}_{i}(k)=\xi_{i}^{\otimes k} \otimes v_{i}, i \in q
$$

memenuhi relasi rekurensi nonhomogen (4) untuk semua $k \geq 0$.

Skalar $\xi_{1}, \xi_{2}, \cdots, \xi_{q}$ ditentukan dengan

$$
\xi_{i}(k)=\bigoplus_{j \in H_{i}}^{\prime} \xi_{j} \oplus^{\prime} \lambda_{i}
$$

dimana $\mathcal{H}_{l}=\left\{j \in \underline{q}: j>i, A_{i j} \neq \mathcal{E}^{\prime}\right\}$.

Bukti. Untuk kasus $i=q$, dengan memerhatikan matriks bentuk normal maka relasi rekurensi (4) menjadi

$$
\boldsymbol{x}_{q}(k+1)=A_{q q} \otimes \boldsymbol{x}_{q}(k) \text {. }
$$

Karena $A_{q q}$ tak tereduksi dan bukan matriks $\mathcal{E}^{\prime}$, maka terdapat $v \in \mathbb{R}_{\min }^{n}$ dan $\xi \in \mathbb{R}$ sehingga barisan

$$
\boldsymbol{x}_{q}(k)=\xi_{q}^{\otimes k} \otimes \boldsymbol{v}_{q}
$$

dengan $\xi_{q}=\lambda_{q}$ memenuhi persamaan (5) untuk semua $k \geq 0$.

Dianggap benar untuk suatu $l+1$, dengan $1<l+1 \leq q$. Sehingga, terdapat vektor $v_{1} . v_{2}, \ldots, v_{q}$ dan skalar $\xi_{1}, \xi_{2}, \ldots, \xi_{q} \in \mathbb{R}$ sedemikian sehingga untuk $k \geq 0$ barisan

$$
\boldsymbol{x}_{i}(k)=\xi_{i}^{\otimes k} \otimes v_{i}, l+1 \leq i \leq q,
$$

memenuhi

$$
\boldsymbol{x}_{\boldsymbol{i}}(k+1)=A_{i i} \otimes \boldsymbol{x}_{\boldsymbol{i}}(k) \oplus^{\prime} \oplus_{j=i+1}^{\prime q} A_{i j} \otimes \boldsymbol{x}_{j}(k), l+1 \leq i \leq q .
$$

Kemudian diperhatikan persamaan

$$
\boldsymbol{x}_{l}(k+1)=A_{l l} \otimes \boldsymbol{x}_{l}(k) \oplus^{\prime} \bigoplus_{j=i+1}^{\prime q} A_{l j} \otimes \boldsymbol{x}_{j}(k) .
$$

Matriks $A_{l l}$ adalah matriks tak tereduksi berukuran $1 \times 1$ sama dengan $\varepsilon^{\prime}$. Selanjutnya jika

$$
\bigoplus_{j=l+1}^{\prime q} A_{l j} \otimes \boldsymbol{x}_{j}(k)=\bigoplus_{j \in \mathcal{H}_{l}}^{\prime} A_{l j} \otimes \boldsymbol{x}_{j}(k)
$$

dengan $\mathcal{H}_{l}=\left\{j \in \underline{q}: j>l, A_{l j} \neq \mathcal{E}^{\prime}\right\}$, maka relasi rekurensi (6) dapat disajikan sebagai berikut.

$$
\boldsymbol{x}_{\boldsymbol{l}}(k+1)=A_{l l} \otimes \boldsymbol{x}_{l}(k) \oplus^{\prime} \bigoplus_{j \in \mathcal{H}_{l}}^{\prime} A_{l j} \otimes \boldsymbol{x}_{j}(k)
$$

Relasi rekurensi (7) akan terpenuhi dengan Teorema 1. Oleh karena itu, dari Teorema 1 terdapat bilangan bulat $K \geq 0$ dan vektor atau skalar $v_{l}$ sedemikian sehingga barisan

$$
\boldsymbol{x}_{l}(k)=\xi_{l}^{\otimes k} \otimes \boldsymbol{v}_{l},
$$

memenuhi relasi rekurensi (7) untuk semua $k \geq K_{l}$, dimana

$$
\xi_{l}=\bigoplus_{j \in \mathcal{H}_{l}}^{\prime} \xi_{j} \oplus^{\prime} \lambda_{l}
$$


selanjutnya untuk setiap $k \geq 0$ barisan $x_{i}(k)$, dimana $l \leq i \leq q$ dapat dituliskan ulang dengan

$$
\boldsymbol{v}_{i}=\xi_{i}^{\otimes K_{l}} \otimes \boldsymbol{v}_{i}, l \leq i \leq q
$$

sehingga didapatkan barisan baru

$$
\boldsymbol{x}_{i}(k)=\xi_{i}^{\otimes K_{l}} \otimes \boldsymbol{v}_{i}, l \leq i \leq q,
$$

yang memenuhi

$$
\boldsymbol{x}_{i}(k+1)=A_{i i} \otimes \boldsymbol{x}_{i}(k) \oplus^{\prime} \bigoplus_{j=i+1}^{\prime q} A_{i j} \otimes \boldsymbol{x}_{j}(k), l \leq i \leq q .
$$

Jadi, berdasarkan hasil tersebut terbukti untuk $l$, dengan $l \leq i \leq q$.

\subsection{Algoritme Eigenmode Matriks Tereduksi Reguler atas Aljabar Min-Plus}

Berdasarkan teorema 1 dan teorema 2 dengan memperhatikan teori eigenmode matriks atas aljabar maks-plus, diperoleh algoritme eigenmode matriks tereduksi reguler atas aljabar min-plus.

1. Diambil $A \in \mathbb{R}_{\min }^{n \times n}$ dimana $A$ merupakan matriks tereduksi reguler.

2. Mengubah matriks $A$ ke dalam bentuk matriks blok segitiga atas.

3. Menghitung nilai eigen dan vektor eigen dari $A_{q q}$ dimana $A_{q q}$ merupakan blok matriks terakhir pada diagonal utama matriks blok segitiga atas dari matriks $A$. Kemudian, diambil $\xi_{q}=\lambda_{q}$ dan $i=q$.

4. Menghitung nilai eigen $\lambda_{i-1}$ dari matriks $A_{(i-1),(i-1)}$.

5. Jika $\lambda_{i-1}<\xi_{i}$ lanjut ke langkah 6 , jika tidak ke langkah 7 .

6. Diambil $\xi_{(i-1)}=\lambda_{(i-1)}$ kemudian menghitung vektor $\boldsymbol{v}_{(i-1)}$ melalui persamaan berikut,

$$
\xi_{(i-1)} \otimes \boldsymbol{v}_{(i-1)}=A_{(i-1),(i-1)} \otimes \boldsymbol{v}_{(i-1)} \oplus^{\prime} \oplus_{j=i}^{\prime q} A_{(i-1), j} \otimes \boldsymbol{v}_{j}
$$

Selanjutnya ke langkah 8.

7. Diambil $\xi_{(i-1)}=\lambda_{i}$ selanjutnya menghitung vektor $v_{(i-1)}$ melalui persamaan berikut

$$
\lambda_{i} \otimes \boldsymbol{v}_{(i-1)}=A_{(i-1),(i-1)} \otimes \boldsymbol{v}_{(i-1)} \oplus^{\prime} \bigoplus_{j=i}^{\prime q} A_{(i-1), j} \otimes \boldsymbol{v}_{j}
$$

Selanjutnya ke langkah 8 .

8. Jika $i-1 \neq 1$ kembali ke langkah 4 , jika tidak maka selesai.

Jadi, diperoleh eigenmode tergeneralisasi dari matriks $A$ yang merupakan pasangan vektor $(\boldsymbol{\eta}, \boldsymbol{v})$ dengan $\boldsymbol{\eta}=$ $\left(\begin{array}{lllll}\xi_{1} & \xi_{2} & \ldots & \xi_{q}\end{array}\right)^{T}$ dan $\boldsymbol{v}=\left(\begin{array}{lllll}v_{1} & v_{2} & \ldots & v_{q}\end{array}\right)^{T}$.

\section{KESIMPULAN}

Berdasarkan Hasil dan Pembahasan diperoleh langkah-langkah untuk menentukan nilai eigen dan vektor eigen matriks tak tereduksi atas aljabar min-plus serta algoritme eigenmode matriks tereduksi reguler atas aljabar min-plus.

\section{DAFTAR PUSTAKA}

[1] Baccelli, F., et al, Synchronization and Linearity, New York: John Wiley and Sons, 2001.

[2] Konigsberg, Z.R., "A Generalized Eigenmode Algorithm for Reducible Regular Matrices over the Max-Plus Algebra", International Matemathical Forum, 4.24. 1157-1171, 2009.

[3] Mursyidah, H. Subiono, "Eigenvalue, Eigenvector, Eigenmode of Reducible Matrix and Its Application", Journal of AIP Conference Proccedings 020044: 1-14, 2017.

[4] Wibowo, A., Wijayanti, K. \& Veronica, R.B.," Penerapan Aljabar Max-Plus pada Pengaturan Sistem Antrian Traffic light”, Unnes Journal of Mathematics 7(2): 192-205, 2018. 
[5] Farlow, K.G., Maxplus Algebra, Master's thesis, Virginia Polytechnic, Institut and State University, Virginia, 2009.

[6] Tam, K.P., Optimizing and Approximating Eigenvectors in Max Algebra, A thesis Submitted to the University of Birmingham for The Degree of Doctor of Philosophy (PHD), 2010.

[7] Novrida, R., .Nilai Eigen dan Vektor Eigen dalam Aljabar Max-Plus, Tesis Program Pasca Sarjana UI, Depok :UI, 2012.

[8] Musthofa \& Bintari, N., Sifat-Sifat Nilai Eigen dan Vektor Eigen atas Aljabar Max Plus, Jurnal Sains Dasar 2(1): 25-31, 2013.

[9] Tunisa, K., Wijayanti, K. dan Veronica, R.B., Nilai Eigen dan Vektor Eigen Matriks atas Aljabar Max-Plus. Unnes Journal of Mathematics 6(2): 189-197, 2017.

[10] Zuliyanto, A., Algoritma Eigenmode Tergeneralisasi untuk Matriks Terreduksi Reguler di dalam Aljabar Maks-Plus, Tugas Akhir untuk memperoleh Gelar Sarjana Matematika pada Jurusan Matematika pada Universitas Sebelas Maret Surakarta, 2012.

[11] Fitria, I., Eigenmode Matriks atas Aljabar Max-Plus, Tugas Akhir untuk memperoleh Gelar Sarjana Sains pada Jurusan Matematika pada Universitas Negeri Semarang, 2019.

[12] Nowak, A. W., The Tropical Eigen Value-Vector Problem from Algebraic, Graphical, and Computational Perspectives, A Thesis Submitted to The University of Bates Colleges for the Degree of Doctor of Philosophy (PHD),2014.

[13] Watanabe, S. \& Watanabe, Y., Min-Plus Algebra and Network, Research Institute for Mathematical Sciences Kyoto University, 041-054, 2014.

[14] Nasichuddin, M., Aplikasi Aljabar Min-Plus dalam Menghitung Nilai Eigen dan Vektor Eigen pada Matriks $n \times n$, Tugas Akhir untuk memperoleh Gelar Sarjana Matematika pada Jurusan Matematika pada Universitas Islam Negeri Maulana Malik Ibrahim Malang, 2018.

[15] Subiono, Aljabar Min-Max Plus dan Penerapannya, 3th ed., Institut Teknologi Sepuluh November, Surabaya, 2015. 
